\title{
Entrevista de Chérif Salif Sy ao jornal Le Soleil ${ }^{1}$
}

\author{
Chérif Salif Sy's interview with the newspaper Le Soleil
}

\section{Chérif Salif Sy*}

O fluxo de homenagens é ininterrupto após o anúncio do falecimento do Professor Samir Amin, em Paris. Por ter compartilhado com ele uma proximidade intelectual e de amizade durante décadas, o que o senhor poderia nos dizer sobre o personagem, seu percurso, e sobretudo, o porquê do seu apego ao Senegal?

Após seus estudos primários e secundários, Samir desembarcou em Paris, em 1948, onde cursou um segundo bacharelado, em matemática elementar, no Liceu Henri IV, um dos mais prestigiosos da França, onde ele se preparará para a seleção para as Grandes Escolas². No início ele não tinha se destinado a fazer economia, mas muito mais as ciências físicas. Ele reencontrou-se estudando economia política para concluir um doutorado em 1957. Paralelamente, havia estudado na Sciences- $\mathrm{Po}^{3}$ e no Instituto de Estatísticas do INSEE (Instituto Nacional de Estatística e Estudos Econômicos).

Sua atividade política e militante na França (1947-1956) lhe deu a oportunidade de estabelecer numerosos contatos nos meios comunistas e anticolonialistas que se revelaram muito úteis posteriormente. De fato, ele foi um militante muito ativo na União Nacional dos Estudantes da França (UNEF), no Partido Comunista, mas igualmente nas organizações estudantis anticolonialistas, nas quais se encontravam principalmente vietnamitas, norte africanos e africanos da África subsaariana. É nesse contexto que ele conheceu uma boa parte daqueles que se tornariam os primeiros dirigentes políticos da África negra francesa pósindependência, assim como os jovens do Oriente Médio que eram muito numerosos naquela época na França, como os sírios e os iraquianos.

Em Paris ele trabalhou durante seis meses no Serviço de Estudos Econômicos e Financeiros (SEEF). Essa experiência lhe proporcionou uma boa formação. Foi lá que ele realmente aprendeu sobre a utilização da macroeconomia no sentido da planificação, de modo mais concreto. Mas ele não queria permanecer em Paris e desejava se inserir em um país onde

\footnotetext{
${ }^{1}$ Entrevista sobre a morte de Samir Amim ao jornal Le Soleil, 14-15 de agosto 2018, Dakar, Senegal.

* Dr. Chérif Salif Sy, diretor de pesquisa do Fórum do Terceiro Mundo e vice-presidente do Fórum Mundial de Alternativas. E-mail: <cherifsalif@orange.sn>.

2 A França dispõe de um sistema paralelo às universidades para a preparação da elite política e científica, de quadros e dirigentes de alto nível para a direção do Estado e das grandes empresas, as Grandes Escolas. (NT).

${ }^{3}$ Sciences-Po é a sigla da Universidade de Ciências Políticas dedicada às ciências sociais em Paris. (NT).
} 
pudesse continuar a desenvolver um trabalho politicamente útil, escolhendo atividades que se conformassem com suas convicções mais profundas.

Em 1956, retornou ao Egito para se lançar na agitação política. Suas ideias e posições políticas estavam fortemente influenciadas pela Conferência Afro-Asiática de Bandung (Indonésia), em 1955 e pela nacionalização do Canal de Suez pelo Presidente Gamal [Abdel] Nasser em 1956. É essa nacionalização que o leva a adiar a defesa de sua tese de doutorado para 1957. Sua atividade política era muito intensa. Sua segunda experiência prática, muito diferente daquela do Egito, foi a opção de ir para o Mali onde ficou de 1960 a 1963.

A escolha do Mali foi determinada pelo fato de que esse país acabava de assumir, em setembro de 1960, uma orientação à esquerda, com o presidente Modibo Keita. Ele se instalou, então, em Bamako como um especialista no Ministério do Planejamento do Mali. Ali ele trabalhou com eminentes economistas franceses, entre eles Jean Bénard e Charles Bettelheim. Samir Amin era encarregado, com seus colegas malineses, da implementação do plano. Ele ocupou esse posto durante três anos, de 1960 a 1963. Contudo, ele viu que certos erros cometidos no Egito pareciam se reproduzir da mesma maneira, o que ele julgava ser totalmente negativo no longo prazo. Ele achava, principalmente, que as escolhas macroeconômicas tinham conteúdos cada vez menos progressistas e levavam em consideração perspectivas cada vez mais de curto prazo.

Um outro erro que ele havia detectado no Mali era a tendência cada vez mais marcada de falar de políticas de recuperação. Ora, para ele, não havia a possibilidade de recuperação no contexto do sistema dominante. A obsessão com a recuperação havia pressionado os dirigentes malineses a enfatizarem a maximização do crescimento, fosse ao preço de uma degradação das condições sociais e, sobretudo, fosse ela ao preço de um desprezo total não só pela democracia política, através do sistema de um partido único, mas também da democracia social, quer dizer, da participação real dos trabalhadores nos processos de tomada de decisão. Esses desvios o levaram a deixar o Mali após três anos de uma experiência prática, que foi também muito rica em aprendizagem e apaixonante.

Após um retiro de três anos na França, Samir desembarcou no Senegal em 1966 (país aberto, relativamente democrático com um embrião de intelectuais progressistas, segundo ele) para se ocupar do Instituto Africano de Desenvolvimento Econômico e de Planificação (IDEP). Sua passagem pelo Instituto parece ter deixado uma marca indelével, a julgar pelas vivas lembranças de todos aqueles que o frequentaram durante aquele período. Antes de deixar o IDEP, Samir Amin tinha preparado sua retaguarda, criando, a partir do IDEP e no seio deste, com seus amigos, outras três instituições, entre elas o Meio Ambiente para o Desenvolvimento da África (ENDA), que se converteu depois no ENDA Terceiro Mundo; o Conselho para o Desenvolvimento da Pesquisa em Ciências Sociais da África (CODESRIA), a partir do modelo do Conselho Latino-Americano de Ciências Sociais (CLACSO). O CODESRIA foi concebido como uma espécie de federação dos institutos e centros de pesquisa universitários e para universitários africanos, para organizar um debate sistemático sobre a natureza dos problemas e dos desafios a enfrentar em todas as suas dimensões. Na verdade, foi uma iniciativa da Fundação Rockefeller que a tinha lançado, mas somente para os países de língua inglesa, com sua sede na Nigéria ou no Quênia. Tendo recebido a informação no momento dareunião de sua constituição, Samir alertou o presidente Senghor. Se tal instituto fosse criado sem

Argum., Vitória, v. 10, n. 2, p. 238-241, maio/ago. 2018. 
os países de língua francesa teria sido uma catástrofe. O presidente Senghor lhe deu imediatamente todo apoio, com o engajamento com o governo do Senegal de assinar um acordo para o sediar. O CODESRIA foi criado com o mesmo acrônimo previsto pela Fundação Rockefeller. Graças a isso, o Senegal se tornou a plataforma científica e intelectual que é até hoje e o CODESRIA, um grande centro de pesquisa com influência internacional, reunindo as universidades e instituições de pesquisa do continente e trabalhando com numerosas universidades e instituições fora do continente, estabelecendo estreitas relações com instituições similares na América Latina e Ásia.

Como sua contribuição foi marcante para a compreensão das questões que moldaram a última metade do século XX na África, em particular para os mecanismos econômicos e políticos que determinaram os destinos de nossos países?

Partindo de sua tese de doutorado sobre o tema: Os efeitos estruturais da integração internacional das economias pré-capitalistas: uma teoria do mecanismo que produziu as economias chamadas de subdesenvolvidas, passando pelos estudos monográficos, entre eles, $O$ Egito de Nasser (1964); Três experiências africanas de desenvolvimento: o Mali, a Guiné e o Ghana (1966); A economia do Maghreb (1966); O desenvolvimento do capitalismo na Costa do Marfim (1967) e O mundo dos negócios senegalês (1969); O Maghreb moderno (1970), o professor Samir Amin apresentou, na Acumulação em escala mundial (1970), a demonstração magistral que, a) ao contrário do que dizia Lênin, o imperialismo não era o estágio superior do capitalismo, mas que este era imperialista desde o seu início, b) que o subdesenvolvimento e o desenvolvimento eram as duas faces da mesma peça. Em outros termos, havia subdesenvolvimento porque havia o desenvolvimento e então um mau desenvolvimento no mundo em seu conjunto.

Professor, o senhor poderia nos explicar a sua transição do conceito de Terceiro Mundo para o de Altermundialismo?

O termo Terceiro Mundo foi forjado por Alfred Sauvy, em 1952, em analogia com o de Terceiro Estado. Ele remete às condições políticas da aparição desse tipo de país no cenário internacional assim como a ideia do desenvolvimento enquanto um objetivo comum, qualitativamente diferente do simples crescimento econômico. Fala-se também de Sul ou da periferia.

O altermundialismo nasceu após os primeiros fóruns sociais mundiais. Se dizia, então, que os movimentos eram anti-mundialistas. Nossa resposta foi que nós éramos por uma outra mundialização e não contra a mundialização. Samir diria que nós somos por uma outra integração mundial.

Após os anos 70, ele rompeu com o dogmatismo marxista para teorizar sobre novas abordagens que procuraram trazer respostas contra as políticas conduzidas sob a direção do FMI e do Banco Mundial, que não dão resultados. Quais são as últimas respostas que ele trouxe aos debates sobre o controle do capital financeiro, sobre a lei implacável dos mercados que marcam a mundialização, que teria sido, enfim, o combate de sua vida?

Argum., Vitória, v. 10, n. 2, p. 238-241, maio./ago. 2018. 
Desde o início dos anos 70, Samir rompeu com o partido comunista francês e com todo o apoio à URSS pelas razões que nós conhecemos. Os movimentos progressistas então lançaram em massa o slogan o socialismo será democrático ou não será. Atualmente, frente aos desvios neoliberais, seu combate se orientou mais para a questão das soberanias, sem a qual nenhum país africano poderá se lançar para a emergência à qual todos os países da África ou ao Sul, têm direito. Bem entendido, nós não gostamos do termo emergente. Para nós, somente o desenvolvimento é um resultado objetivo.

Para evocar sua herança, pode-se dizer que ele teria criado uma escola de pensamento? Quais seriam, então, seus fundamentos, seu abecedário de qualquer modo?

Uma escola de pensamento anticapitalista, anti-imperialista, contra o neoliberalismo (quer dizer a submissão das economias ao mercado, considerado como omnisciente) e a submissão voluntária.

\section{Chérif Salif Sy}

Diretor de pesquisa do Fórum do Terceiro Mundo. Vice-presidente do Fórum Mundial de Alternativas. 